\title{
THE ESSENCE OF DIFFERENTIATED TARIFFS AND FOREIGN EXPERIENCE IN THEIR IMPLEMENTATION
}

\author{
J.O. Obidjonov \\ Tashkent State Technical University acting representative of head-office JSC "UzbekEnergo".
}

\begin{abstract}
The article describes the approaches to improving the systems for differentiating electricity tariffs: reducing their regional differentiation; refusal from cross-subsidization by categories of consumers and by reliability; introduction of tariff differentiation by levels of electricity supply reliability.
\end{abstract}

\section{Introduction}

The development of market relations in the electric power industry necessitates further improvement of the tariff regulation mechanism, development of a methodology for the formation of economically justified tariffs and its individual components.

Differentiation of tariffs is a means of accounting for objective differences in the conditions of production, transmission and consumption of electricity. The mechanism of differentiation arose simultaneously with the emergence of tariffication/tariffing as such. In 1921, two rate tariffs were introduced, which, in contrast to one rate, stimulate the smoothing of the electricity consumption schedule.

Their objective basis is the additional costs of meeting the demand that is strongly changing during the day. The same function is performed by one rate tariffs introduced since the late $70 \mathrm{~s}$ for small consumers, differentiated by time of day.

\section{Main part}

An important stage in the development of the tariff differentiation mechanism was the selection of consumer groups (1967), each of which, depending on the voltage class of the supply networks, the power consumption mode, the amount of power consumed, is assigned as an individual tariff. The mechanism of tariff differentiation turned out to be burdened with an alien "social component": a number of tariffs were justified not by objective differences in costs, but by social benefits for some groups of consumers. The state provided such benefits, but did not pay, - the financial costs were born by other categories of consumers, mainly industrial enterprises (which turned out to be one of the factors in the decline in industrial production). This crosssubsidization still exists today. In the eighties, another modification of cross-subsidization appeared - in terms of reliability: different consumers are provided with a different degree of reliability of electricity supply with correspondingly different costs, but the cost difference is not reflected in the tariff. Basic postulates for electricity consumers, in addition to the amount of supplied (not supplied) power and energy, are important for the frequency and duration of planned and unplanned outages. For a number of consumers, the amount of damage depends on when the electricity supply was interrupted. Other reliability meters are also possible. In general, indicators should be easily measurable and ensure settlements amongst subjects with the least difficulty. At the initial stage of introducing tariff differentiation in terms of reliability, in the light of these requirements, power outages and undersupply of energy should be recognized as the most suitable meters. Electricity market entities should be granted the following economic freedoms:

- the consumer's choice of the desired level of electricity supply reliability with subsequent financial responsibility to the supplier for paying this level and economic responsibility for all risks associated with this decision;

- the choice by the electricity supply company of a method to ensure the required level of electricity supply reliability with full responsibility for its obligations and risks. The reliability of electricity supply is ensured both by observing its contractual level and by compensating for losses (damages) from interruptions in electricity supply in excess of it. The tariff (tariff component) for the reliability of electricity supply should be regulated, and it is not the level of reliability itself that is regulated, but the price of a unit of reliability offered in response to the level of reliability of supply requested by the consumer.

The tariff system should encourage energy enterprises to look for effective ways to ensure the reliability of electricity consumers, and the latter - to 
rationalize their requirements for the reliability of their supply, to bring requests in line with financial capabilities. Reliability requires costs, therefore, it should be considered as a commodity that has a price, offered on the market and sold in the system of contractual relations between business entities. The basis of this system should be electricity supply; contracts; accession; rendering services for the transmission of electricity and for operational dispatch control, as well as additional system services. All documents need to specify the mutual requirements for reliability. Responsibility to the consumer the electricity supply company is responsible for the reliability of its electricity supply. The latter (or qualified consumers) must establish a contractual relationship in terms of reliability with all involved energy companies, while various contract schemes are possible. Reliability tariffs should be set at all boundaries of interaction between market entities. Due to the complex, hierarchical system of contractual relations in terms of reliability between energy companies and market entities, the form of tariffs for reliability and the reliability indicators used in them should be such that they can be easily combined and "broadcast" to all pairs of counterparties. Within the boundaries fixed in the contracts, all market participants must be liable for damage caused by a power failure, damage to equipment, lost profits. In case of compensations exceeding the values established by contracts, the subjects are released from liability for damage caused by a violation of the reliability of power supply. In this case, the risk insurance system should work. The energy supplying organization may perform the insurance functions itself or delegate them to another organization specializing in the field of risk insurance. In our opinion, electricity tariffs should include three components:

- the tariff for maintaining the system reliability of the node in the zone of responsibility of the system operator (the same for all consumers powered by this node);

- an individual tariff for maintaining the reliability of power supply in the area of responsibility of the grid company (depends on the level of reliability chosen by the consumer);

- individual insurance component (depends on the amount of damage).

The introduction of differentiation by levels of reliability cannot affect the value of the average system tariff in terms of covering the costs of ensuring the contractual level of reliability, since the differentiation mechanism only redistributes these costs between consumers in accordance with their requests for the reliability of electricity supply. The tariff increase may be affected by the introduction of the insurance part, but such insurance is not mandatory. Payment for reliability according to the proposed tariff differentiation scheme is subject to the principle: the higher the contractual reliability, the more expensive electricity is for the buyer. In general, if the contractual value of the reliability level exceeds the standard, the tariff has a premium, if on the contrary - a discount. When the actual value of the reliability level is higher than the contractual value, no changes in the financial calculations (provided for by the standard electricity supply contract) occur. Otherwise, economic sanctions are imposed on the supplier (the electricity supply company), which he, in turn, broadcasts to the subjects of the power industry or the insurance company, depending on the situation. The consumer sets a payment that suits him for the capacity and energy not supplied to him in comparison with the agreed level and pays the corresponding tariff for reliability. All damages arising from failures in its electricity supply are compensated by the supplying party. If the payment for the reliability of a consumer is lower than the amount of damage paid to him, the energy company has an incentive to improve the reliability of the electricity supply to this consumer until further increase in its cost becomes more expensive than saving from the payment of damages. The consumer will also strive to most accurately determine the degree of reliability of his electricity supply that is feasible for payment. Its overestimation will lead to an overpayment for the "reliable" component of the tariff, underestimation - to unpaid damages. Thus, the proposed system of relations between the subjects of the electricity market encourages the optimization of the level of reliability of both suppliers and consumers of electricity.

Let us consider examples of retail tariff systems in countries with a high degree of electricity and electricity market development.

France at the end of the 1940s, more than 13 thousand different tariffs were ordered. As the first attempt at such a streamlining for BCPs, the country's electricity administration introduced the so-called "green" tariff. In the second half of the 1980s, the restructuring of the tariff system was characterized by the emergence of "blue" and "yellow" tariffs. The existing tariffs are divided into these three types, depending on the connected capacity of the consumer [2].

1) "Blue" tariff differentiates the cost of electricity supply depending on the load capacity, increasing it for more powerful consumers, and also divides it into groups of industrial, agricultural and household consumers. The tariff for each group includes a fixed monthly or annual subscription fee and a fee for the consumed electricity. In the "blue" tariff there are two daily zones: day (16 hours) and night ( 8 hours). The cost of electricity in the daytime zone is 1.7 times higher than at night. Consumers receiving electricity at the "blue" tariff do not have the opportunity to exceed the declared 
load capacity, since in this case they are automatically disconnected from the network.

2) "Yellow" tariff includes payment of maximum load and EC of day (16 hours) and night ( 8 hours) zones for winter (November - March) and summer (April October) periods. The ratio of the cost of electricity in the day and night zones is 2.3 in winter and 1.9 in summer.

3) "Green" tariff applies to three groups of consumers - A, B and C, in accordance with the amount of connected capacity. Consumers of each group have a choice between four tariff options. An important feature of this tariff system is the ability to control the consumer's load through telecontrol channels.

In the basic version for group A, five tariff zones are taken into account (three for winter and two for summer). The basic option for groups B and C takes into account eight tariff zones.

About $15 \%$ of consumers connected to high voltage grids use a "green" tariff with an option to reduce the load during peak periods (peak electricity is 25 times more expensive at night).

The introduction of the "green" tariff has ensured sustainable equalization of GBV. The ratio of average peak loads to summer off-peak loads over the 20 years of tariff application decreased from 2 to 1.6. The winter filling rate of the daily UGP increased from $72 \%$ to $87 \%$.

Japan. By voltage, they are divided into three categories: consumers of electricity of low voltage (200 $\mathrm{V})$, high voltage $(6 \mathrm{kV}$, contract capacity $50-2000 \mathrm{~kW})$ and extra-high voltage $(20-140 \mathrm{kV}$, over $2000 \mathrm{~kW})$. ECs also offer special night-time rates; differentiated by the season; agricultural; reserve; for melting snow and ice and others. With the consent of the Ministry of Foreign Trade and Industry, some large consumers may conclude special contracts with ES for the supply of electricity at reduced (against normal) tariffs, provided that they undertake to bring their EC in accordance with the requirements set forth in the contract or comply with all ES notices and orders. For low-capacity BCPs, the summer tariff is about $10 \%$ higher [3].

In the commercial sector, for consumers with a contractual load of $500 \mathrm{~kW}$ and above, whose annual night electricity consumption exceeds $30 \%$ of the total electricity consumption, a discount has been introduced for the use of electricity at night. It is $20 \%$ and applies to the value of the EC in excess of the $30 \%$ threshold.

Electricity tariffs in the communal sector are the same for all ten power grids in the country. Standard tariffs for all consumers are based on a two-rate principle. The main board is proportional to the current setting of the power supply: for $20 \mathrm{~A}$ it is twice as high as for $10 \mathrm{~A}$. The additional board is a direct three-stage: the tariff for the 1 st stage is $75 \%$, for the 2 nd stage $100 \%$, for 3 th $-110 \%$.
USA. The 1978 Federal Law on the Regulation of the PURPA Utility Company provides for the following types of tariffs for energy supply companies [4]:

1) daily tariffs reflecting the change in the price of electricity depending on the time of day and daily ST in electricity sphere;

2) seasonal tariffs reflecting the change in the price of electricity depending on the annual ST in electricity sphere;

3) tariffs by categories of consumers (industrial, household, etc.);

4) preferential tariffs for consumers agreeing to breaks in the power system (or a significant decrease in the volume of power supply) during periods of maximum power load;

5) socially oriented tariffs, which provide for a change in the price of supplied electricity depending on the demographic characteristics of individual regions, the social structure of the population, the family ratio, birth rate, etc.

The FERC Federal Regulatory Commission has established unified forms of calculating the costs of creating and operating electrical installations, production and distribution of electricity, based on which the procedure for setting tariffs is determined.

Since 1976, time-of-day tariffs have been widely used in the United States. According to the data, commercial and industrial consumers are covered by these tariffs by more than 50\%, while residential consumers are covered by about $1 \%$. The structures of tariffs for different ESs are varied, for large consumers two-rate tariffs are used, while the additional rate is usually differentiated by two daily zones, the main rate is often stepwise.

The highest average selling price is set in the residential sector, which is 1.5 times or higher than the corresponding figure for industrial consumers. The price level for commercial consumers is only 5-6\% lower than in the residential sectorv[5-8].

Average monthly prices for electricity for all consumer groups are maximum in July-August and minimum in December- February. According to the data, for the average household consumer, a connection fee of $\$ 4 /$ month is provided, a power consumption fee of $\$ 8 / \mathrm{kW}$ per month, and a fee for consumed electricity of 3-13 cents / $\mathrm{kWh}$ (for different regions of the United States). It should be noted the close relationship with consumers of US EC marketing specialists, the development of tariffs that meet the requirements of consumers.

Sweden. Since 1973, day (from 6 to 22 hours) and night (from 22 to 6 hours), as well as summer (MayAugust) and winter (September-April) rates of the differentiated tariff have been applied. Tariffs are divided into industrial and utility tariffs. The industrial tariff is two-rate, payment is made both for the 
connected capacity and for the consumed electricity. For the household consumer, the tariff is divided into main and additional. The main tariff is applied in the municipal sector for consumers with a significant volume of in a limited period of time and for consumers with a small volume of electricity supply the year, and the additional tariff is applied in the residential sector. There is a possibility of introducing a rolling tariff, which is set for the next 24 hours, and then revised; the consumer is completely dependent on the market conditions [9-11].

Germany. In the retail trade of electricity, tariffs differentiated by time zones are applied for various categories of consumers. For residential consumers, the following tariff is typical: the cost of electricity on weekdays from 20 to 6 hours and on weekends - $17 \mathrm{pf} /$ $\mathrm{kWh}$ (1.0 in oe), during peak hours on weekdays from 9 to 13 hours - $37 \mathrm{pf} / \mathrm{kWh}$ (2.2), in the rest - "normal" time - $27 \mathrm{pf} / \mathrm{kWh}$ (1.6). The introduction of such a tariff had a positive effect on ST: the night load increased by $7 \%$, on weekends - by $4-5 \%$, on weekdays the load fell by $3-4 \%$, and during peak hours - by $10 \%$ [12].

Great Britain. Even though bullet price changes every 0.5 hours, the practical application of spot rates is limited even in the sphere of wholesale sales. In the process of retail sales from DRM to specific consumers, various types of tariffs are practically applied, designed to interest consumers: constant and time dependent; with payment for power and tariffs, considering the possibility of interruption of power supply Electricity tariff systems applied abroad are very diverse; their differentiation is widespread according to the following indicators: 1) categories of consumers; 2) time zones; 3) ES voltage levels; 4) ES reliability levels. It should be noted that the tariff setting process is oriented towards consumers, taking into account their capabilities, requirements and wishes; work on creating alternative tariff systems for various groups of consumers.

The examples of the considered differentiated tariff systems are applicable in terms of expedient ratio of tariff

rates.

Improving the economic mechanism for the formation of electricity tariffs is an urgent task in modern conditions. The paper proposes methods for eliminating crosssubsidization of electricity consumers and the use of tariffs to stimulate energy conservation among consumers and electricity producers.

This will allow to correctly reflect the ratio of variable costs of the power system in each zone of the day of the electric load schedule, which will increase the efficiency of using differentiated by time of day electricity tariffs for regulated consumer groups.
The role of differentiated tariffs as an instrument of energy saving for consumers and producers of electricity is shown.

The proposed tariffs for electricity and capacity will eliminate the unprofitable sale of electricity by the JSC. An urgent task is to differentiate the rate for electricity of the two-part rate by time zones. This will make it possible to link tariffs with the optimization of power plant operating modes

\section{References}

1.Taslimov A.D., Rismukhammedov D.A. Methodical development for the educational laboratory "Automated system for monitoring and metering of electricity" /, Tashkent, Tashkent State Technical University-2011. P-31.

2.http://energetika.in.ua/ru/books/book-5/part-4/section3

3.https://so-ups.ru/fileadmin/files/company/markets/dr/ publication/dr_japan_energ_market_07_16.pdf 4.https://www.hse.ru/data/2014/12/18/1103302584/

5. Changes in the structure of the US electric power industry (Summary of the report of the US Department of Energy) // Energetik 2001. -№ 10-12.

6.https://www.np-sr.ru/ru/market/cominfo/foreign/index. $\mathrm{htm} \# 10$

7. https://www.spot.uz/ru/2018/09/05/energy/

8. Kolcun M., Griger V., Muhlbacher J. Electric power system operation control. Bratislava, Mercury-Smecal. 2004. 299-page.

9.Allayev, K.R., Fedorenko, G.M.,Postnikov, V.I.,Ostapchuk, L.B. Asynchronous generators as power system's natural dampers. 43rd International Conference on Large High Voltage Electric Systems 2010, CIGRE 20102010, 9p43rd International Conference on Large High Voltage Electric Systems 2010, CIGRE 2010; Paris; France; 22 August 2010.

10.Fazylov, Kh.F.,Allaev, K.R. Analysis of the operation of an electrical system during simultaneous operation of synchronous and asynchronous generators. Power engineering New York Volume 18, Issue 3, 1980, Pages 81-88.

11.Fazylov, Kh.F.,Allaev, K.R. Asynchronous turbogenerators with stator excitation and the prospects for their utilization. Power engineering New York Volume 23, Issue 2, 1985, Pages 7-13.

12.Fazylov, Kh.F.,Allaev, K.R. Calculation and experimental analysis of conditions of electrical power systems containing induction generators Power Engineering New York Volume 27, Issue 6, 1989, Pages 27-34. 